\title{
Bounded Solidarity in Cross-National Encounters: Individuals Share More with Others from Poor Countries but Trust Them Less
}

\author{
Felix Bader, ${ }^{a}$ Marc Keuschnigg ${ }^{b}$
}

a) Technical University of Kaiserslautern; b) Linköping University

Abstract: Globalization makes cross-national encounters increasingly common. Hesitant cooperation across national, ethnic, and cultural boundaries, however, undercuts the microlevel stabilizers of global integration and, most importantly, the willingness to share with and place trust in members of other social groups. In a 109-country online experiment, we convey information on interaction partners' nationalities to indicate membership in a broader in- or out-group, cultural distance, and perceived material neediness-or status differences more generally-to 1,674 participants in incentivized games of generosity (dictator game) and trust (trust game). We find consistent evidence for in-group favoritism and-against this benchmark-demonstrate that individuals across the globe share more with but place less trust in interaction partners from poor countries and that cultural distance moderates this status effect.

Keywords: cross-country cooperation; discrimination; international inequality; in-group favoritism; cultural distance; trust

Citation: Bader, Felix, and Marc Keuschnigg. 2020. "Bounded Solidarity in Cross-National Encounters: Individuals Share More with Others from Poor Countries but Trust Them Less." Sociological Science 7: 415432.

Received: June 5, 2020

Accepted: July 22, 2020

Published: September 8, 2020

Editor(s): Jesper Sørensen, Delia Baldassarri

DOI: 10.15195/v7.a17

Copyright: (C) 2020 The Author(s). This open-access article has been published under a Creative Commons Attribution License, which allows unrestricted use, distribution and reproduction, in any form, as long as the original author and source have been credited. (C) (i)
UMANS sustain high levels of cooperation, regularly choosing behaviors that 1 benefit others even in conflict with their self-interests (Axelrod 1984; Nowak and Sigmund 2005; Dawes et al. 2007; Cohn et al. 2019), and generosity toward members of disadvantaged groups has been found in a series of laboratory studies (Eckel and Grossman 1996; Brañas-Garza 2006; Liebe and Tutic 2010; van Doesum, Tybur, and van Lange 2017). At the same time, we are liable to in-group biases and discriminatory behavior, which lead to partisanship, selective group solidarity, and the breakdown of cooperation along social boundaries (Homans 1950; Hewstone, Rubin, and Willis 2002; Baldassarri and Grossman 2013; Hruschka and Henrich 2013). The lack of cooperation across national, ethnic, and cultural fault lines is consequential for human prosperity in a globalized economy as well as for our ability to tackle global challenges, including climate change, public health, and mass migration. Cooperation across social boundaries requires bottom-up support-most notably, a willingness to share with and trust in members of other "tribes."

Cooperative behavior hinges on interaction partners' identities, and bringing such information into social experimentation is particularly important in sociological research. In this article, we test the theoretical implications of bounded solidarity in human cooperation when generosity and trust are conditional on group membership, cultural distance, and material neediness-or status differences more generally. We focus on generosity as a normative decision on the willingness to share with members of other social groups, and we examine trust as a strategic decision to invest in boundary-crossing exchanges. Drawing on recent experimental 
results, we recapitulate the behavioral baseline of "in-group favoritism," namely, stronger cooperative orientations in encounters that do not cross social boundaries (Baldassarri and Grossman 2013; Dorrough and Glöckner 2016; Romano et al. 2017; Fiedler et al. 2018; Schaub, Gereke, and Baldassarri 2020). We then provide arguments suggesting an interaction partner's social status may exert opposing effects on sharing and on trust. More precisely, we expect the main effect of material neediness to be positive with regard to generosity but negative for trust, and we theorize on the negative influence of cultural distance on sharing and trusting that moderates status effects in cross-national contexts.

We implement a novel experimental design using Amazon Mechanical Turk (MTurk), which allows us to measure the contingency of cooperative decisions on the identities of interaction partners in cross-national settings. Our design conveys interaction partners' nationalities to indicate group membership in a broader in- or out-group, dyadic cultural distances, and status differences to 1,674 participants in 109 countries. We measure cooperation in two distinct incentivized decision situations: the dictator game (DG) and the trust game (TG). The DG is a standard behavioral measure of altruism, wherein a participant receives a sum of money and chooses anonymously the fraction she passes to another, passive, person. Experimenters typically interpret giving as a manifestation of generosity and compliance with fairness norms (Eckel and Grossman 1996; Bicchieri 2006; Baldassarri and Grossman 2013). The TG, on the other hand, mimics an investment decision by introducing the possibility of nonreciprocity by a second mover, and-unlike in the DG-participants are required to form expectations on second movers' likelihood of reciprocation. First-mover behavior in the TG is interpreted as the willingness to place trust in an interaction partner. In combination with information about interaction partners' identities, both games provide behavioral measures of the extent to which cooperative behavior hinges on perceptions of social closeness and status. We find that conveying participants' nationalities induces in-group favoritism in both decision situations. By differentiating sharing and trusting, our results map the predictions of a model for bounded solidarity in human cooperation that expects solidarity to be moderated vertically by status differences and horizontally by cultural distance.

In the remainder, we expand on our theoretical argument as to why we expect interaction partners' status to have a negative effect on generosity and a positive effect on trust and how cultural distance narrows the scope of these opposing effects. We then describe our design, data collection, and results. We conclude with a discussion of our work's relevance and limitations.

\section{Bounded Solidarity}

Low cross-boundary cooperation, some have argued, follows from humans' preferences to interact with similar others (Homans 1950; Hewstone et al. 2002; Hruschka and Henrich 2013). Humans classify individuals into social groups based on observable characteristics (Billig and Tajfel 1973) and are more willing to share resources with members of their own groups (Habyarimana et al. 2007; Whitt and Wilson 2007). 
Various theoretical accounts suggest that such "in-group favoritism" stems from entrenched distastes for interactions with outsiders (Becker 1957), prejudice (Allport 1954), or perceived group threat (Williams 1964), from the positive social identities individuals derive from favorable appraisals of in-group members (Tajfel and Turner 1986), as well as from inferences of others' normative behavior based on observable group memberships (Arrow 1973). Ascriptive characteristics, such as ethnicity and status, play a crucial explanatory role in social identity theory (Tajfel and Turner 1979, 1986), positing human reliance on readily observable markers to categorize interaction partners in order to generalize prior interaction experiences to unfamiliar others. In a similar vein, Lamont and Molnár (2002) highlight the role of intersubjectively constructed borderlines in categorizing individuals and groups. Such symbolic boundaries can manifest in social interactions, fostering discrimination against out-group members (Lamont and Fournier 1992). In-group interactions, on the other hand, take place under widely accepted coordination rules that reduce uncertainty and stipulate normative orientations (Axelrod 1984; Fearon and Laitin 1996; Nowak and Sigmund 2005). Furthermore, prior studies have documented the role of positive expectations about in-group interactions in fostering increased honesty and trustworthiness (Brewer and Campbell 1976; Dinesen and Sønderskov 2015). Consequently, perceived similarities not only promote normative orientations and trust but also make cultural tastes and expected discriminatory behaviors mutually reinforcing. These arguments predict that generosity and trust will be lower in cross-boundary interactions.

What is more, individuals value more highly the well-being of others to whom they feel closer (Hruschka and Henrich 2013) and rate justice principles as more important in closer encounters (Hafer and Olson 2003). Even in anonymous one-off encounters, a noticeable share of people erroneously expect to meet others again if they perceive them as socially close and, because of this imaginary shadow of the future, act in accordance with higher beliefs in others' normative behavior and reciprocity (Delton et al. 2011). Consequently, individuals have been reported to cooperate more readily with others to whom they feel socially close (Kayser, Schwinger, and Cohen 1984; Brown 2000) and who fall within their personal "radius of trust" (Harrison 1985:7-8). In cross-national contexts, these behavioral patterns imply that the discrete in-group versus out-group effect extends to a gradual formulation according to which cooperativeness decreases monotonically with the perceived cultural distance to one's interaction partner.

Perceptions of others' economic neediness - or social status more generallyconstitute a second layer of humans' bounded solidarity. Greater generosity toward members of disadvantaged groups is well-established in laboratory research (Eckel and Grossman 1996; Brañas-Garza 2006; Liebe and Tutic 2010; van Doesum et al. 2017). This has been explained as a consequence of relative income security (Hruschka and Henrich 2013), a means of demonstrating superiority in social exchange (Blau 1964), or "noblesse oblige"-a social norm encouraging higherstatus individuals to treat the disadvantaged benevolently (Liebe and Tutic 2010).

Orthogonal motives exist regarding the strategic decision to place trust. Disadvantaged groups more often rely on immediate rewards (Banerjee and Duflo 2011; Haushofer and Fehr 2014; Schaub et al. 2020), and economic disadvantages are 
associated with lower trust toward strangers (Knack and Keefer 1997)—factors that reduce perceived trustworthiness. In cross-ethnic studies, low-status groups like migrants in Europe (Zhang et al. 2019) or blacks in the United States (Doleac and Stein 2013) are well-documented as eliciting lower trust. After all, placing trust is a risky investment decision informed by beliefs in an interaction partner's compliance with the reciprocity norm (Bicchieri 2006; Elster 2007). Trustees of higher material neediness have greater relative incentives to compromise trust, and thus, so the argument goes, individuals will be less inclined to trust the needy. These arguments suggest that lower-status interaction partners evoke more altruistic generosity but are met with less strategic trust. Speaking to this argument, Katz, Cohen, and Glass (1975) report that "cross-ethnic altruism" depends critically on whether cooperative behavior involves risks: white Americans behave more prosocially toward blacks in a safe environment but much less so when risks are involved (for more recent US findings, see also Schaub et al. [2020]).

This conceptualization of bounded solidarity provides four quantitative targets for experimental testing: (1) Both generosity and trust are highest in in-group interactions and (2) monotonically decrease as perceived cultural distance increases. (3) Generosity increases with the perceived neediness of the recipient, whereas (4) trust decreases the greater the recipient's perceived neediness. Combining proposition 2 with propositions 3 and 4, we further expect that cultural distance narrows the scope conditions of the opposing status effects on generosity and trust. If cultural distance to the preferred interaction partner becomes too great, the generosity-toward-the-poor effect and the trust-in-the-rich effect cross-fade or reverse because the effects of distance and status can operate in opposite directions. Using the interplay of two distinct decision situations, our design differentiates between altruistic behavior (DG) toward out-groups and the poor and strategic behavior based on others' expected behavior (TG).

Studies on cross-ethnic cooperation within the same country-using similar behavioral games - often confound the effects of status and social distance (Doleac and Stein 2013; Zhang et al. 2019) because in many countries individuals ethnically or culturally distant from the majority group are typically also of lower status. For the United States, Schaub et al. (2020) separate the effects by varying the interaction partner's income and race independently. They report reduced trust in low-income partners, especially when they are black, but a positive effect of receiver's low status on the generosity bestowed. A series of cross-country experiments have used nationality as an indicator of group membership and countries' economic prosperity as a salient source of participants' status. Beyond in-group favoritism (Romano et al. 2017), some report a positive generosity effect (Cappelen et al. 2013; Fiedler et al. 2018), whereas others report a negative trust effect (Özer, Zheng, and Ren 2014) toward participants from poor countries. But no existing crossnational study consistently differentiates generosity-driven cooperation from trustdriven cooperation. What is more, prior research covers only handfuls of different countries (between 2 and 17), thereby dangerously conflating measures of cultural distance and social status. This has led to inconsistent results-including out-group favoritism (Özer et al. 2014; Kim et al. 2017), no generosity-toward-the-poor effect (Stoddard and Leibbrandt 2014), no trust-in-the-rich effect (Goerg et al. 2016), and 
a positive relation of cultural distance and cooperation (Dorrough and Glöckner 2016; Fiedler et al. 2018). Our design combines two distinct decision situations with data collection in considerably more countries in order to reconcile these seemingly contradictory findings.

\section{Sampling and Design}

Our online experiment carries standardized decision situations into the heterogeneous living conditions of 1,674 MTurk workers from 109 countries. Subjects interacted anonymously via the Internet and thus connected virtually to a diverse set of participants from other countries while rooted in their home countries. We are well aware of the various self-selection processes leading individuals from different countries to join an online workforce. Our design prioritizes participant heterogeneity over representativity. For our empirical tests, variance in cultural distance and in perceived status is key to disentangling their partial effects on boundary-crossing cooperation. Unlike studies comparing rates of cooperation between locations (Henrich et al. 2001; Cohn et al. 2019; Baldassarri 2020), we do not aim to elicit differences in prosocial behavior across countries or estimate the effects of specific country pairings. Instead, we focus on participants' reactions to information about their interaction partners and thus the interpretation of treatment effects pooled over participants from all countries covered.

Recruiting. MTurk, accessible from most countries, sustains one of the world's largest pools of crowdworkers. Recruiting ran from March 4 to June 3, 2017, and was open to one-time-only participation. To increase sample heterogeneity, we limited the recruitment of workers from the United States and India, who together make up more than 80 percent of the pool (Ipeirotis 2017). For the same reason, we restricted the recruitment of participants from Canada, the Philippines, the United Kingdom, and Venezuela. In effect, we recruited 50 percent of our sample from poorer countries and 50 percent from rich countries (using World Bank's estimates of per-capita income for classification; World Bank [2018a]). We provide a detailed sample description in Tables A1 and A3 in the online supplement. We informed interested workers about payment and the duration of the experiment before they signed up.

Randomization. Upon sign-up, we collected participants' countries of residence and randomly assigned each arrival to a specific sequence of games and boundarycrossing interactions (see online supplement A2). We randomly matched each participant to a new partner for each game. To avoid waiting time (and drop outs), actual matching occurred only before payoff: to determine payment of both participants, we randomly paired one of each finalist's decisions with a complementary decision randomly drawn from the pool of participant responses that were completed the same day. We made this procedure common knowledge. This study uses no deception.

Instructions. We refrained from multilanguage instructions, using simple English common to most crowdsourced tasks on MTurk (see online supplement A5). To monitor participants' understanding of tasks, we included a set of control questions after the actual experiment (to avoid the priming of specific strategies). We allowed 
participants who provided wrong answers to complete the experiment and receive payment. We then flagged them in our multivariate analysis using an indicator variable. The indicator shows no significant association with the treatment effect (see Table A4 in the online supplement).

Decision situations. Each arrival participated in two distinct decision situations in which socially desirable behaviors diverge from decision-makers' self-interests. The behavioral games reveal compliance with fairness norms and expectations of reciprocity (Bicchieri 2006; Elster 2007). In the DG, a participant receives a sum of money and chooses the fraction (0 percent to 100 percent) she passes to another, passive, person (Kahneman, Knetsch, and Thaler 1986). ${ }^{1}$ The DG is an anonymous one-shot interaction without strategic motives for sharing-the decision situation bears no risk of sanctions or loss of reputation-such that a purely selfinterested participant would pass nothing to another person. Experimenters thus interpret giving as a manifestation of generosity (Eckel and Grossman 1996) and the compliance with fairness norms (Baldassarri and Grossman 2013). The TG, on the other hand, mimics an investment decision by introducing the possibility of nonreciprocity by a second mover (Berg, Dickhaut, and McCabe 1995), thus changing the interaction context to a strategic situation. In our implementation, both the first mover (trustor) and the second mover (trustee) receive an equally sized stake $^{2}$ and the trustor chooses the fraction she sends to the trustee. We double this amount, and the trustee then decides how much of the doubled amount she sends back to the trustor. First-mover behavior in the TG reveals whether participants trust in their interaction partner. Placing trust depends on the first mover's belief in the second mover's trustworthiness and, unlike in the DG, first movers are required to form expectations on second movers' likelihood of reciprocation. Transfers are profitable only if the trustee sends back more than half of the investment. We collected back-transfers using the strategy method (Rauhut and Winter 2010), eliciting trustees' responses to all possible first-mover decisions. We asked each participant to make three sequential decisions in the DG and the TG, respectively, playing each game with a randomly selected counterpart from their own country, from a poor country, and from a rich country. We gave no feedback in between games to secure independence of sequential behavior.

Treatments. In the baseline in-group condition, we inform each participant that they have been matched with another participant from their own country. In the out-group condition, we show a list of five countries on screen and inform the focal participant that her counterpart hails from one of these countries. ${ }^{3}$ Our instructions read, for example, "Player B is a Mechanical Turk worker from Brazil, Bulgaria, Serbia, China or the Philippines" (see online supplement A5). Our design leverages behavioral differences in response to these lists and we interpret behavioral differences from the baseline as a direct measure of discrimination against out-group members. As discrimination is theoretically expected to operate through attitudes and stereotypes regarding groups, we manipulate status and cultural distance on the level of national identity rather than on the level of individual affluence or lifestyle (see Zhang et al. [2019] for a similar argument). Our treatment circumvents loaded frames that labels like "poor" versus "rich" or "close" versus "distant" might have evoked. The country-list implementation precludes potential 
Table 1: Characteristics of the countries used as treatments.

\begin{tabular}{lcccccccc}
\hline Country & PDI & IDV & MAS & UAI & LTO & IVR & $\begin{array}{c}\text { Cultural distance } \\
\text { to the US }\end{array}$ & $\begin{array}{c}\text { GDP } \\
\text { per capita }\end{array}$ \\
\hline Brazil & 69 & 38 & 49 & 76 & 44 & 59 & 72 & 15,484 \\
Bulgaria & 70 & 30 & 40 & 85 & 69 & 16 & 106 & 20,329 \\
China & 80 & 20 & 66 & 30 & 87 & 24 & 112 & 16,807 \\
Mexico & 81 & 30 & 69 & 82 & 24 & 97 & 87 & 18,149 \\
Philippines & 94 & 32 & 64 & 44 & 27 & 42 & 84 & 8,343 \\
Serbia & 86 & 25 & 43 & 92 & 52 & 28 & 106 & 15,090 \\
Turkey & 66 & 37 & 45 & 85 & 46 & 49 & 79 & 27,916 \\
\hline Australia & 38 & 90 & 61 & 51 & 21 & 71 & 8 & 47,047 \\
Canada & 39 & 80 & 52 & 48 & 36 & 68 & 18 & 46,378 \\
Germany & 35 & 67 & 66 & 65 & 83 & 40 & 71 & 50,716 \\
Italy & 50 & 76 & 70 & 75 & 61 & 30 & 62 & 39,817 \\
Japan & 54 & 46 & 95 & 92 & 88 & 42 & 100 & 43,876 \\
Korea & 60 & 18 & 39 & 85 & 100 & 29 & 122 & 38,260 \\
United Kingdom & 35 & 89 & 66 & 35 & 51 & 69 & 28 & 43,877 \\
\hline
\end{tabular}

Notes: Gross domestic product (GDP) per capita 2017 in current international PPP\$ (World Bank 2018b). IDV, Individualism Index; IVR, Indulgence versus Restraint Index (Hofstede, Hofstede, and Minkov 2010); LTO, Long-term Orientation Index; MAS, Masculinity Index; PDI, Power Distance Index; UAI, Uncertainty Avoidance Index.

affection or animosity effects from specific country pairings. To effectively conceal our research questions, this treatment is comparatively weak, giving priority to unbiased results over larger treatment effects. The country lists contain either poor or rich countries, with varying cultural distances from the focal participant's own country. We draw the lists from a pool of seven middle-income and seven high-income countries (Table 1) featuring both marked cultural differences and sufficient numbers of MTurk workers. The country lists randomly assign and fully factorialize interaction partners' cultural distance and perceived material neediness. We vary the material neediness of the interaction partner using her country's gross domestic product (GDP) per capita. The example above lists five countries-Brazil, Bulgaria, Serbia, China, and the Philippines-with relatively low per-capita income. We measure cultural distance based on country scores (0-100) in six sociocultural dimensions (Hofstede Insights [2018]; see also Dorrough and Glöckner [2016]; Fiedler et al. [2018]), and we quantify interaction partners' dyadic cultural distances as the mean of the six-dimensional Euclidean distances between the subject's home country and each of the five counterpart countries displayed on screen. Table 1 lists the Euclidean distances to the United States, but note the much larger matrix of distances in the 109-countries data set (see Table A1 in the online supplement).

Questionnaire. Following the experiment, participants answered questions regarding their sociodemographic backgrounds, personal experiences with experimental games, and their physical and social surroundings during participation (see online supplement A3). We administered the questionnaire at the end of the experiment to minimize respondents' motivation to misreport. 
Payoff. Each participant received a $\$ 1$ show-up fee, and we incentivized decisions (\$2 endowment in the DG, \$1 for each player in the TG). Stake levels in this range have proven sufficient to minimize social-desirability effects on MTurk (Keuschnigg, Bader, and Bracher 2016). Participants received on average \$1.86. At a mean completion time of 12.1 minutes, this scales to an hourly wage of $\$ 9.30$. We debriefed and paid each participant within a maximum of 36 hours.

Our design allows us to focus exclusively on within-subject variation in participants' behavior when estimating the causal effects of interacting with either a compatriot ("in-group") or a participant from a poor ("out-group, low status") or a rich country ("out-group, high status"). When examining the impact of the counterpart countries' characteristics on cooperation, we compare the behaviors between subjects treated with the randomly assigned country lists. Here, we use multivariate linear regressions of treatment effects on a set of individual-level and context variables, keeping decision-makers' sociodemographic backgrounds constant (see online supplement A4 for a full tabulation). We calculate partial effects of GDP differences between the countries of rich and poor counterparts (Figure 1B) and partial effects of cultural differences (Figure 2) on the measured treatment effects. The Hofstede scale for cultural characteristics is not available for all countries. We thus restrict our analysis of the gradual impact of wealth differences and cultural distances to the 1,557 participants from the 75 countries covered (Figures $1 \mathrm{~B}$ and 2, and Tables A3 and A4 in the online supplement). Restricting the sample also for the within-analysis (Figure 1A) does not change our results.

\section{Results}

Comparing participants' responses to our treatments in a within-subject perspective, Figure 1A identifies significant in-group favoritism regarding both generosity and trust. The mean transfer in the DG is 42.1 percent in the in-group and 38.6 percent in the out-group conditions $(t=9.78, p<0.001)$. Similarly, the mean transfer in the TG is 52.6 percent versus 49.8 percent $(t=6.54, p<0.001)$. Although small in magnitude, these effects are well in line with proposition 1. Against this benchmark, our data support proposition 3 with a positive generosity effect of +1.4 percentage points toward participants from poor vis-à-vis rich foreign countries $(t=4.16, p<0.001)$. In placing trust-proposition 4 - on the other hand, participants favor interaction partners from rich countries over those from poor countries $(-0.9$ percentage points, $t=2.05, p=0.040)$. Corroborating the key touchstones of bounded solidarity, status effects are orthogonal in generosity and in trust.

If the perceived status of the interaction partner indeed drives these discrepancies, gaps in cooperation with poor- and rich-country counterparts should intensify with greater GDP difference between the poor and the rich countries on screen. ${ }^{4}$ In line with this argument, we find that the premium sent to the poor in a situation of generosity and to the rich in a situation of trust increases slightly with the GDP difference between rich-country and poor-country counterparts (Figure 1B). Note that, to identify this effect, we must assume participants to be well aware of eco- 

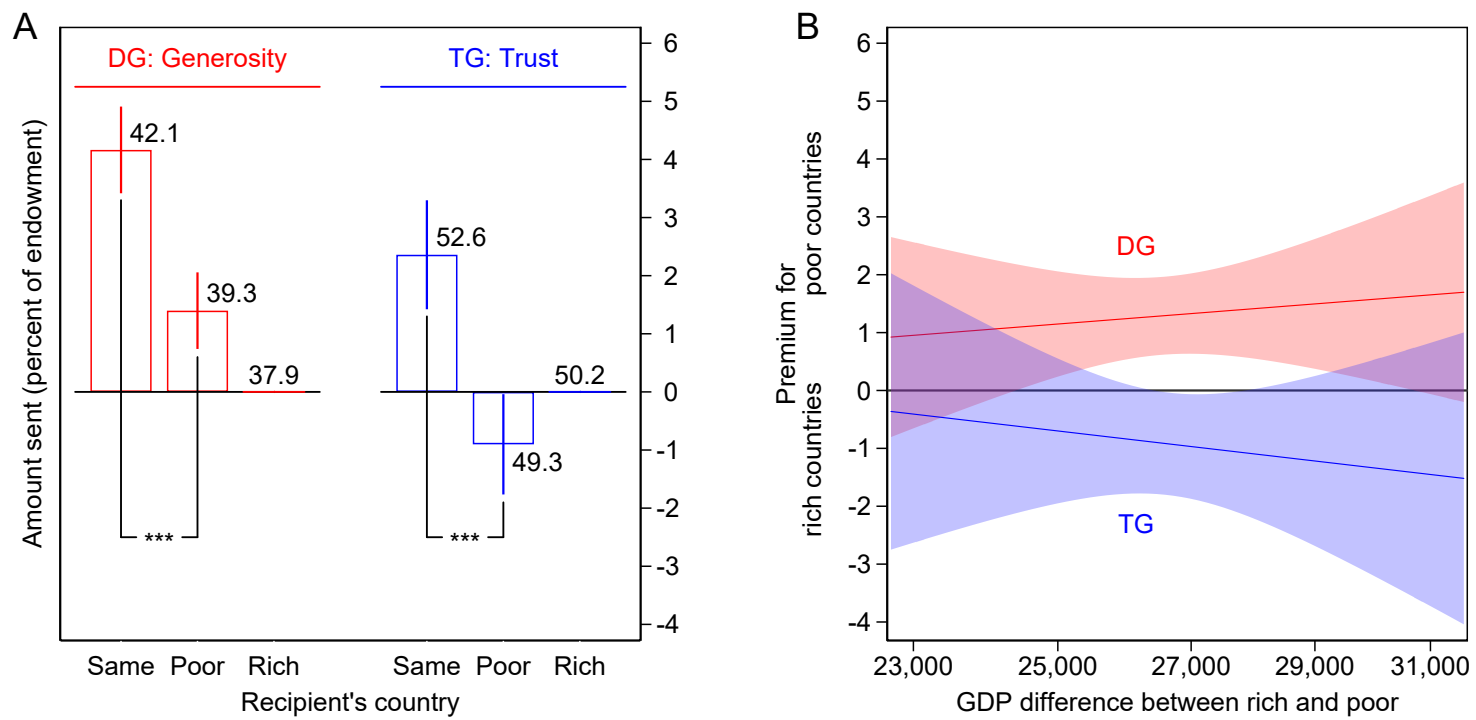

Figure 1: $(A)$ Average rates of cooperation (mean transfers as a percentage of the endowment) reveal significant in-group favoritism, a generosity effect toward poor-country counterparts, and a trust effect toward richcountry counterparts. We report paired two-sided $t$ tests (and 95\% confidence intervals) that contrast elicited behavior with the mean transfers to counterparts from rich countries (*** indicates differences significant at the level $p<0.001$ ). (B) The opposing status effects increase with perceived material neediness difference. We plot the predicted difference in mean transfers to poor minus rich countries in the dictator game (DG; red) and the trust game (TG; blue) against the difference between the (logged) average gross domestic product (GDP) per capita in current international PPP\$ of rich and of poor countries (95\% confidence intervals based on robust standard errors). The status effects from panel $A$ are greater when GDP differences are larger.

nomic prosperity in the countries listed on screen. Small effect sizes are thus hardly surprising.

Our theorizing further implies that the cultural distance between the decisionmaker's home country and interaction partners' countries should amplify estimates of in-group favoritism (proposition 2) and narrow the scope of the reported status effects. In Figure 2, we use our design's independent variation of cultural distance and status to plot predicted differences of mean transfers to poor-country counterparts minus those to rich-country counterparts against cultural distances of the focal participant's country to the poor (Figure 2A) or rich countries (Figure 2B) listed on screen. Cultural distance monotonically reduces both forms of cooperation, meeting target (proposition 2). Note that Figure 2B depicts cultural distances to rich countries, and positive effects indicate increased cooperation with the poor. Recipients from poor countries evoke significantly greater generosity (Figure 2A, red line) but only while cultural distance remains small. Vice versa, recipients from rich countries receive greater strategic trust (Figure 2A, blue line), particularly when the benchmark poor-country counterparts are culturally distant. Replicating this finding on the scope conditions of status effects, Figure 2B shows a complementary pattern for cultural distance to rich countries. As expected, a generosity-toward-thepoor effect as well as a trust-in-the-rich effect is only evident when cultural distance 

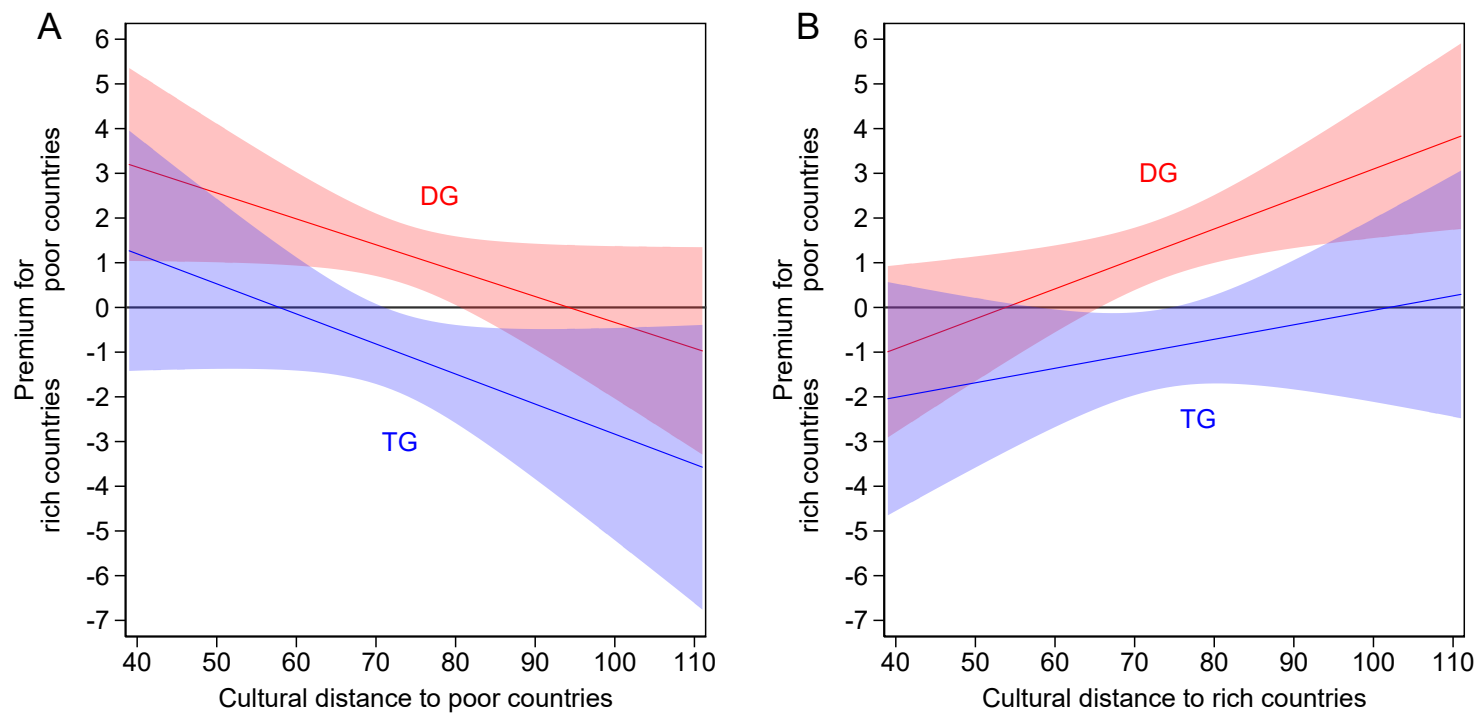

Figure 2: Cultural distance moderates the distinct status effects on generosity and trust. We plot the mean difference in transfers to poor minus rich countries in the dictator game (DG; red) and the trust game (TG; blue) against the cultural distance to either $(A)$ poor-country counterparts or $(B)$ rich-country counterparts ( $95 \%$ confidence intervals based on robust standard errors). Generosity and trust decrease with cultural distance. The status effect is stronger when the cultural distance to poor countries is small in the DG (see panel $A$ ). Likewise, the status effect in the TG is evident only if the cultural distance to rich countries is small (see panel $B$ ).

to the respective interaction partner is sufficiently small. In other words, individuals are particularly generous toward poor and close counterparts in contrast to rich and distant counterparts. On the other hand, participants place significantly greater trust in rich and close counterparts than in poor and distant counterparts.

\section{Discussion}

Ego's willingness for cooperation often depends on alters' social identities, and eliciting such categorizations in experimental designs is particularly important in sociological research. Taking into account that most laboratory findings are based on rather narrow and homogeneous populations, we further believe that crowdsourced online experiments can serve as an important complement to bringing together diverse samples of experimental participants (Bader et al. 2019). This online experiment carried two standardized decision situations, the dictator game (DG) and the trust game (TG), into the heterogeneous living conditions of a diverse sample of crowdworkers from 109 countries. Our treatments indicated membership in a broader in- or out-group as well as dyadic cultural distances and status differences between the focal decision-makers and their interaction partners. Our results provide support for a conceptualization of bounded solidarity that recognizes social distances and status differences as important moderators of human cooperation. 
Prior studies on cross-national cooperation operationalized cooperation in one dimension only-as either a normative or a strategic decision-within only a handful of countries, leading to a cross-contamination of estimated status and distance effects (Özer et al. 2014; Dorrough and Glöckner 2016; Kim et al. 2017; Fiedler et al. 2018). Our study, which covers more than a hundred countries, shows that generosity and trust are highest in in-group interactions and decrease monotonically over increased cultural distance. Generosity decreases as the recipient's perceived status rises, indicating that justice principles can guide altruistic behavior in crossboundary interaction. Placing trust, on the other hand, rests on expectations of reciprocity, which we find increasing with recipient's status. The interplay of two structurally different decision situations-a normative choice about sharing and a strategic one about trusting - provides indications as to the underlying mechanisms that impede cross-boundary cooperation. In the DG, we find no evidence for tastebased discrimination (Becker 1957) against the poor, whereas our findings in the TG point to an inference-based version of discrimination (Arrow 1973) grounded on expectations about others' likelihood of reciprocation.

Ironically, we find trustworthiness to be higher among participants from poor countries than among those from rich countries. The mean back-transfer in the TG while keeping underlying sociodemographics constant, is 41.8 percent versus 38.6 percent $(t=2.88, p=0.004) .{ }^{5}$ This result suggests that biased beliefs of reciprocity drive the trust-in-rich effect. It is worth noting that even small individual biases can accumulate into serious aggregate disadvantages, especially when minute differences in perceived trustworthiness lead to consequential yes-or-no decisions, such as in competition for foreign direct investment between individuals from different countries where early successes tend to snowball into larger cumulative advantages (for example, China; see Liu, Wang, and Wei [2001]; OECD [2002]). These findings propose that biased beliefs about individuals from poor and culturally distant countries lacking trustworthiness are an essential obstacle to cross-national cooperation. The structural discrimination emerging from such faulty perceptions also impedes the integration of culturally distant immigrants and may hinder the poorest economies' integration into global markets.

For an alternative explanation of the observed status effects, one may speculate that reduced solidarity with people from rich countries is due less to relative affluence than to perceptions of "white privilege" or remembrance of European colonialism. Our data do not support this argument. Treatment effects in the subgroup of participants who only interacted with counterparts from "white" rich countries $(n=69)$ are equivalent to those for participants whose country lists included the "non-white" rich countries Japan or Korea $(n=1,605)$.

We chose "weak" treatments-lists of counterparts' home countries-to convey information on interaction partners' cultural identities and material neediness. The country lists conceal our research objectives, promoting unbiased results over artificially large effect sizes. Small effect sizes are thus hardly surprising, particularly considered against the background of the various self-selection processes guiding individuals of different countries to join an online workforce. In rich countries, for example, Amazon Mechanical Turk (MTurk) may be a source of additional income for those lacking other employment opportunities. In poorer countries, on 
the other hand, access to MTurk is skewed toward the educated and technically well-equipped. Crowdworkers from richer countries thus belong to lower income classes, but crowdworkers in poor countries are more affluent than their average compatriot. $^{6}$ This renders our estimated status effects conservative. We should further anticipate educated and, particularly in the United States, more liberal (Chandler et al. 2019) crowdworkers to hold fewer prejudices against out-groups and the more culturally distant. Some, on the other hand, may lack the knowledge to categorize all potential counterpart countries as either rich or poor-another reason to expect rather weak effects of our treatments. Importantly, the observed behavioral patterns consistently confirm the theoretical expectations of bounded solidarity in a cross-national context.

Clearly, our design prioritizes participant heterogeneity more than representativity. For our empirical tests, variance in perceived material neediness and in cultural distance were of critical importance. Maximizing the number of participant countries while allowing for small samples within each country (see Table A1 in the online supplement), our design reveals the contingency of cooperative decisions on the identities of interaction partners in a very broad cross-national setting. The large number of countries permits independent variation of cultural distance and relative affluence between interaction partners, allowing cultural heterogeneity to vary not only between the counterpart countries at large but, crucially, also within the set of rich and the set of poor counterpart countries, respectively.

Our focus on treatment effects-participants' reactions to information about their interaction partners-rather than on comparing country-averaged behaviors within treatment conditions renders the desideratum of participant representativity within each country considerably less important than in studies comparing rates of cooperation between locations (Henrich et al. 2001; Cohn et al. 2019). We do not estimate country-specific effects but use the conveying of others' nationalities to understand its effects on ego's decisions regarding sharing and trusting in randomized boundary-crossing interactions. Our design choices do not permit inferences on country-specific rates of cooperation or the effects of specific country pairings. In either case, valid estimates require representative sampling of experimental participants-a goal particularly hard to attain in the many heterogeneous countries in the developing world. It is clear that the lack of within-country representativity impedes the estimation of heterogeneous treatment effects within countries or country groups.

Despite these limitations, our findings on bounded solidarity have direct implications for cooperation in day-to-day encounters. In diverse work teams, for example, the effects of status differences and cultural distance may lead to foreseeable but preventable problems. Corporate decision-makers and employees alike may benefit from learning that colleagues from minority groups or from less affluent countries are not foci for altruistic giveaways and can be reliable partners. Perceived dissimilarities are not only problematic in that people from different cultures sometimes disagree over preferred outcomes (Lieberman and McClendon 2013) or basic values (Jehn, Northcraft, and Neale 1999) but also because social distance itself makes people skeptical of cooperation, even in situations wherein culture plays no immediate role. A related finding on labor market discrimination 
overlaps with our results (Pager, Western, and Bonikowski 2009): due to lack of trust, minority applicants often find themselves diverted to jobs other than those for which they originally applied, and these "charitable" offers tend toward positions with lower wages and lesser occupational status.

Trust across social boundaries is also important to achieving long-term integration of immigrants, and generosity alone cannot solve the societal challenges of a diversifying world. The frequency of interactions spanning national, ethnic, and cultural fault lines makes it increasingly important to understand the social constraints on cross-boundary cooperation, particularly as anti-immigrant sentiment grows in many countries (Kuntz, Davidov, and Semyonov 2017) and the willingness to support redistributive welfare states falls off in increasingly heterogeneous societies (Eger and Breznau 2017). Our ability to tackle global challenges requires effective strategies for mitigating discriminatory behavior in economic exchanges. The willingness to share with the poor as identified in our data gives some hope for microlevel stabilizers of cross-boundary cooperation, but distrust in the poor and reluctance to share with or to trust in culturally distant others clearly diminishes humanity's capacity for cooperation across salient fault lines.

\section{Notes}

1 We only allowed multiples of 10 percent of the endowment as transfers in both the DG and the TG.

2 A second-mover endowment reduces first-mover altruism as a motive for sending money and provides a cleaner measurement of trust (Johnson and Mislin 2011).

3 Our design includes no control group lacking information on interaction partner's identity. By design, participants in a neutral control group would have less information about their counterparts, and on MTurk would most likely assume their interaction partner to be a typical crowdworker, effectively eliciting behaviors reflecting attitudes toward US citizens.

4 GDP differences range from PPP\$22,704 to PPP\$31,604, depending on the particular poor and rich countries to which we exposed randomly the focal participant.

5 Note that for this estimate we compare decisions between participants and, unlike when calculating our primary findings, we examine observational data because randomizing participants' home countries is not possible. Similarly, data from the Global Preference Survey (Falk et al. 2018) do not show the expected positive relationship between GDP per capita and positive reciprocity $(t=0.54, p=0.591$, own calculations).

6 In our data, people from low- or middle-income countries earn $\$ 1,155$ more $(t=14.41$, $p<0.001$ ) than their respective country's average income (measured by monthly GDP per capita), whereas participants from high-income countries earn $\$ 2,116$ less ( $t=36.83$, $p<0.001)$ than their country's average income.

\section{References}

Allport, Gordon W. 1954. The Nature of Prejudice. Reading, MA: Addison-Wesley.

Arrow, Kenneth J. 1973. "The Theory of Discrimination." Pp. 3-33 in Discrimination in Labor Markets, edited by O. Ashenfelter and A. Rees. Princeton, NJ: Princeton University Press. 
Axelrod, Robert. 1984. The Evolution of Cooperation. New York, NY: Basic Books.

Bader, Felix, Bastian Baumeister, Roger Berger, and Marc Keuschnigg. 2019. "On the Transportability of Laboratory Results." Sociological Methods E Research, first published on February 20, 2019 as https://doi .org/10.1177/0049124119826151.

Baldassarri, Delia. 2020. "Market Integration Accounts for Local Variation in Generalized Altruism in a Nationwide Lost-Letter Experiment." Proc Natl Acad Sci U S A 117:2858-63. https://doi.org/10.1073/pnas.1819934117.

Baldassarri, Delia, and Guy Grossman. 2013. "The Effect of Group Attachment and Social Position on Prosocial Behavior: Evidence from Lab-in-the-Field Experiments." PLoS One 8:e58750. https://doi.org/10.1371/journal . pone.0058750.

Banerjee, Abhijit V., and Esther Duflo. 2011. Poor Economics: A Radical Rethinking of the Way to Fight Global Poverty. New York, NY: Public Affairs.

Becker, Gary S. 1957. The Economics of Discrimination. Chicago, IL: University of Chicago Press.

Berg, Joyce, John Dickhaut, and Kevin McCabe. 1995. "Trust, Reciprocity, and Social History." Games and Economic Behavior 10:122-42. https://doi .org/10.1006/game.1995.1027.

Bicchieri, Cristina. 2006. The Grammar of Society: The Nature and Dynamics of Social Norms. Cambridge, UK: Cambridge University Press.

Billig, Michael, and Henri Tajfel. 1973. "Social Categorization and Similarity in Intergroup Behaviour." European Journal of Social Psychology 3:27-52. https://doi .org/10.1002/ ejsp. 2420030103.

Blau, Peter M. 1964. Exchange and Power in Social Life. New York, NY: Wiley.

Brañas-Garza, Pablo. 2006. "Poverty in Dictator Games: Awakening Solidarity." Journal of Economic Behavior and Organization 60:306-20. https://doi .org/10.1016/j . jebo. 2004. 10.005.

Brewer, Marilynn B., and Donald T. Campbell. 1976. Ethnocentrism and Intergroup Attitudes: East African Evidence. New York, NY: Wiley.

Brown, Rupert. 2000. Group Processes. Oxford, UK: Blackwell.

Cappelen, Alexander W., Karl O. Moene, Erik Ø. Sørensen, and Bertil Tungodden. 2013. "Needs versus Entitlements: An International Fairness Experiment." Journal of the European Economic Association 11:574-98. https://doi .org/10.1111/jeea.12000.

Chandler, Jesse, Cheskie Rosenzweig, Aaron J. Moss, Jonathan Robinson, and Leib Litman. 2019. "Online Panels in Social Science Research: Expanding Sampling Methods beyond Mechanical Turk." Behavior Research Methods 51:2022-38. https://doi.org/10.3758/ s13428-019-01273-7.

Cohn, Alain, Michel André Maréchal, David Tannenbaum, and Christian Lukas Zünd. 2019. "Civic Honesty around the Globe." Science 365:70-3. https://doi .org/10 . 1126/ science.aau8712.

Dawes, Christopher T., James H. Fowler, Tim Johnson, Richard McElreath, and Oleg Smirnov. 2007. "Egalitarian Motives in Humans." Nature 446:794-6. https : //doi .org/10 . 1038/ nature05651.

Delton, Andrew W., Max M. Krasnow, Leda Cosmides, and John Tooby. 2011. "Evolution of Direct Reciprocity under Uncertainty Can Explain Human Generosity in One-Shot Encounters." Proc Natl Acad Sci U S A 108:13335-40. https://doi.org/10.1073/pnas . 1102131108. 
Dinesen, Peter T., and Kim M. Sønderskov. 2015. "Ethnic Diversity and Social Trust: Evidence from the Micro-Context." American Sociological Review 80:550-73. https ://doi .org/10. $1177 / 0003122415577989$.

Doleac, Jennifer L., and Luke C. D. Stein. 2013. "The Visible Hand: Race and Online Market Outcomes." Economic Journal 123:F469-92. https://doi .org/10.1111/ecoj . 12082.

Dorrough, Angela Rachael, and Andreas Glöckner. 2016. "Multinational Investigation of Cross-Societal Cooperation." Proc Natl Acad Sci U S A 113:10836-41. https : //doi .org/ 10.1073/pnas. 1601294113.

Eckel, Catherine C., and Phillip J. Grossman. 1996. "Altruism in Anonymous Dictator Games." Games and Economic Behavior 16:181-91. https://doi .org/10.1006/game.1996.0081.

Eger, Maureen A., and Nate Breznau. 2017. "Immigration and the Welfare State: A CrossRegional Analysis of European Welfare Attitudes." International Journal of Comparative Sociology 58:440-63. https://doi .org/10.1177/0020715217690796.

Elster, Jon. 2007. Explaining Social Behavior: More Nuts and Bolts for the Social Sciences. Cambridge, UK: Cambridge University Press.

Falk, Armin, Anke Becker, Thomas Dohmen, Benjamin Enke, David Huffman, and Uwe Sunde. 2018. "Global Evidence on Economic Preferences." Quarterly Journal of Economics 133:1645-92. https://doi.org/10.1093/qje/qjy013.

Fearon, James D., and David D. Laitin. 1996. "Explaining Interethnic Cooperation." American Political Science Review 90:715-35. https://doi .org/10.2307/2945838.

Fiedler, Susann, Dshamilja Marie Hellmann, Angela Rachael Dorrough, and Andreas Glöckner. 2018. "Cross-National In-Group Favoritism in Prosocial Behavior: Evidence from Latin and North America." Judgment and Decision Making 13:42-60.

Goerg, Sebastian J., Heike Hennig-Schmidt, Gari Walkowitz, and Eyal Winter. 2016. "In Wrong Anticipation: Miscalibrated Beliefs between Germans, Israelis, and Palestinians." PLoS One 11:e0156998. https://doi .org/10.1371/journal . pone.0156998.

Habyarimana, James, Macartan Humphreys, Daniel N. Posner, and Jeremy M. Weinstein. 2007. "Why Does Ethnic Diversity Undermine Public Goods Provision?" American Political Science Review 101:709-25. https://doi .org/10.1017/S0003055407070499.

Hafer, Carolyn L., and James M. Olson. 2003. "An Analysis of Empirical Research on the Scope of Justice." Personality and Social Psychology Review 7:311-23. https : //doi .org/10. 1207/S15327957PSPR0704_04.

Harrison, Lawrence E. 1985. Underdevelopment is a State of Mind: The Latin American Case. Cambridge, MA: Center for International Affairs, Harvard University.

Haushofer, Johannes, and Ernst Fehr. 2014. "On the Psychology of Poverty." Science 344:8627. https://doi.org/10.1126/science.1232491.

Henrich, Joseph, Robert Boyd, Samuel Bowles, Colin Camerer, Ernst Fehr, Herbert Gintis, and Richard McElreath. 2001. "In Search of Homo Economicus: Behavioral Experiments in 15 Small-Scale Societies." American Economic Review 91:73-8. https://doi.org/10. 1257/aer.91.2.73.

Hewstone, Miles, Mark Rubin, and Hazel Willis. 2002. "Intergroup Bias." Annual Review of Psychology 53:575-604. https://doi .org/10.1146/annurev .psych.53.100901.135109.

Hofstede, Geert, Gert J. Hofstede, and Michael Minkov. 2010. Cultures and Organizations: Software of the Mind. New York, NY: McGraw Hill.

Hofstede Insights. 2018. "Compare Countries." Retrieved July 22, 2018. https://www . hof stede-insights. com/product/compare-countries/. 
Homans, George C. 1950. The Human Group. New York, NY: Harcourt, Brace \& World.

Hruschka, Daniel Jacob, and Joseph Henrich. 2013. "Economic and Evolutionary Hypotheses for Cross-Population Variation in Parochialism." Frontiers in Human Neuroscience 7:559. https://doi.org/10.3389/fnhum.2013.00559.

Ipeirotis, Panagiotis G. 2017. "MTurk Tracker." Retrieved March 4, 2017. http:// demographics.mturk-tracker.com/\#/countries/all.

Jehn, Karen A., Gregory B. Northcraft, and Margaret A. Neale. 1999. "Why Differences Make a Difference: A Field Study of Diversity, Conflict, and Performance in Workgroups." Administrative Science Quarterly 44:741-63. https : //doi .org/10. 2307/2667054.

Johnson, Noel D., and Alexandra A. Mislin. 2011. "Trust Games: A Meta-Analysis." Journal of Economic Psychology 32:865-89. https://doi .org/10.1016/j . joep.2011.05.007.

Kahneman, Daniel, Jack L. Knetsch, and Richard H. Thaler. 1986. "Fairness and the Assumptions of Economics." Journal of Business 59:S285-300. https ://doi . org/10 . 1086/296367.

Katz, Irwin, Sheldon Cohen, and David Glass. 1975. "Some Determinants of Cross-Racial Helping Behavior." Journal of Personality and Social Psychology 32:964-70. https://doi . org/10.1037/0022-3514.32.6.964.

Kayser, Egon, Thomas Schwinger, and Ronald L. Cohen. 1984. "Laypersons' Conceptions of Social Relationships: A Test of Contract Theory." Journal of Social and Personal Relationships 1:433-58. https://doi.org/10.1177/0265407584014003.

Keuschnigg, Marc, Felix Bader, and Johannes Bracher. 2016. "Using Crowdsourced Online Experiments to Study Context-Dependency of Behavior." Social Science Research 59:68-82. https://doi.org/10.1016/j.ssresearch.2016.04.014.

Kim, Byung-Yeon, Syngjoo Choi, Jungmin Lee, Sokbae Lee, and Kyunghui Choi. 2017. "Do Institutions Affect Social Preferences? Evidence from Divided Korea." Journal of Comparative Economics 45:865-88. https://doi.org/10.1016/j.jce.2016.08.004.

Knack, Stephen, and Philip Keefer. 1997. "Does Social Capital Have an Economic Payoff? A Cross-Country Investigation." Quarterly Journal of Economics 112:1251-88. https: //doi.org/10.1162/003355300555475.

Kuntz, Anabel, Eldad Davidov, and Moshe Semyonov. 2017. "The Dynamic Relations between Economic Conditions and Anti-Immigrant Sentiment: A Natural Experiment in Times of the European Economic Crisis." International Journal of Comparative Sociology 58:392-415. https://doi.org/10.1177/0020715217690434.

Lamont, Michèle, and Marcel Fournier, eds. 1992. Cultivating Differences: Symbolic Boundaries and the Making of Inequality. Chicago, IL: University of Chicago Press.

Lamont, Michèle, and Virág Molnár. 2002. "The Study of Boundaries in the Social Sciences." Annual Review of Sociology 28:167-95. https ://doi .org/10.1146/annurev. soc . 28.110601.141107.

Liebe, Ulf, and Andreas Tutic. 2010. "Status Groups and Altruistic Behaviour in Dictator Games." Rationality and Society 22:353-80. https://doi.org/10.1177/ 1043463110366232.

Lieberman, Evan S., and Gwyneth H. McClendon. 2013. "The Ethnicity-Policy Preference Link in Sub-Saharan Africa." Comparative Political Studies 46:574-602. https : //doi .org/ 10.1177/0010414012463876.

Liu, Xiaming, Chengang Wang, and Yingqi Wei. 2001. "Causal Links between Foreign Direct Investment and Trade in China." China Economic Review 12:190-202. https: //doi.org/10.1016/S1043-951X (01) 00050-5. 
Nowak, Martin A., and Karl Sigmund. 2005. "Evolution of Indirect Reciprocity." Nature 437:1291-8. https://doi.org/10.1038/nature04131.

OECD. 2002. Foreign Direct Investment in China: Challenges and Prospects for Regional Development. Paris, FR: OECD Publishing.

Özer, Özalp, Yanchong Zheng, and Yufei Ren. 2014. "Trust, Trustworthiness, and Information Sharing in Supply Chains Bridging China and the United States." Management Science 60:2435-60. https://doi .org/10.1287/mnsc.2014.1905.

Pager, Devah, Bruce Western, and Bart Bonikowski. 2009. "Discrimination in a Low-Wage Labor Market: A Field Experiment." American Sociological Review 74:777-99. https: //doi.org/10.1177/000312240907400505.

Rauhut, Heiko, and Fabian Winter. 2010. "A Sociological Perspective on Measuring Social Norms by Means of Strategy Method Experiments." Social Science Research 39:1181-94. https://doi.org/10.1016/j.ssresearch.2010.06.009.

Romano, Angelo, Daniel Balliet, Toshio Yamagishi, and James H. Liu. 2017. "Parochial Trust and Cooperation across 17 Societies." Proc Natl Acad Sci U S A 114:12702-7. https : //doi.org/10.1073/pnas.1712921114.

Schaub, Max, Johanna Gereke, and Delia Baldassarri. 2020. "Does Poverty Undermine Cooperation in Multiethnic Settings? Evidence from a Cooperative Investment Experiment." Journal of Experimental Political Science 7:27-40. https ://doi .org/10.1017/XPS . 2019.19.

Stoddard, Olga, and Andreas Leibbrandt. 2014. "An Experimental Study on the Relevance and Scope of Nationality as a Coordination Device." Economic Inquiry 52:1392-407. https://doi.org/10.1111/ecin.12097.

Tajfel, Henri, and John C. Turner. 1979. "An Integrative Theory of Intergroup Conflict." Pp. 33-47 in The Social Psychology of Intergroup Relations, edited by W. Austin and S. Worchel. Monterey, CA: Brooks Cole.

Tajfel, Henri, and John C. Turner. 1986. "The Social Identity Theory of Intergroup Behavior." Pp. 7-24 in Psychology of Intergroup Relations, edited by S. Worchel, and W. Austin. Chicago, IL: Nelson-Hall.

van Doesum, Niels J., Joshua M. Tybur, and Paul A. M. van Lange. 2017. "Class Impressions: Higher Social Class Elicits Lower Prosociality." Journal of Experimental Social Psychology 68:11-20. https://doi.org/10.1016/j.jesp.2016.06.001.

Whitt, Sam, and Rick K. Wilson. 2007. "The Dictator Game, Fairness and Ethnicity in Postwar Bosnia." American Journal of Political Science 51:655-68. https://doi.org/10.1111/j . 1540-5907.2007.00273.x.

Williams, Robin M. 1964. Strangers Next Door: Ethnic Relations in American Communities. Englewood Cliffs, NJ: Prentice-Hall.

World Bank. 2018a. "World Development Indicators: World Bank Analytical Classifications." Retrieved July 7, 2018. http://databank.worldbank.org/data/download/ site-content/OGHIST.xls.

World Bank. 2018b. "World Development Indicators: GDP per capita, PPP (current international \$)." Retrieved July 22, 2018. https://data. worldbank.org/indicator/NY.GDP. PCAP.PP.CD.

Zhang, Nan, Amelie Aidenberger, Heiko Rauhut, and Fabian Winter. 2019. "Prosocial Behaviour in Interethnic Encounters: Evidence from a Field Experiment with High- and Low-Status Immigrants." European Sociological Review 35:582-97. https : //doi . org/10. 1093/esr/jcz030. 
Acknowledgments: We thank Hanna Nau, Leona Przechomski, and Fabian Thiel for excellent research assistance and Amelie Aidenberger, Johanna Gereke, Wojtek Przepiorka, and Heiko Rauhut for discussions. This research received funding from the German Research Foundation (KE 2020/2-1). M.K. further acknowledges the Swedish Research Council (2018-05170). Address correspondence to felix.bader@sowi.uni-kl.de.

Felix Bader: Department of Social Sciences, Technical University of Kaiserslautern. E-mail: felix.bader@sowi.uni-kl.de.

Marc Keuschnigg: Institute for Analytical Sociology, Linköping University.

E-mail: marc.keuschnigg@liu.se. 